\title{
Effects of stimuli present during oral morphine administration on withdrawal and subsequent consumption
}

\author{
ANDREA POWERS SOBRERO and MARK E. BOUTON \\ University of Vermont, Burlington, Vermont
}

\begin{abstract}
We assessed the role of conditioning in controlling morphine self-administration and withdrawal in three experiments. In the first two experiments, rats were trained to drink a sucrose-morphine solution in one of two distinctive cage and room environments. Based upon a compensatoryresponse model of drug tolerance as applied to drug dependence, we predicted that withdrawal would be less intense if the animals' environment were switched prior to removal of the drug, and furthermore, that relapse would be more likely when the drug was reintroduced in the original context. Withdrawal was assessed by monitoring body-weight loss and behavioral symptoms. No evidence was obtained that could support a compensatory-response theory using this particular paradigm of drug dependence. In Experiment 3, taste was manipulated as the drug-associated stimulus. During withdrawal, the animals received either plain water or a saccharin-quinine solution that tasted like the original saccharin-morphine solution. There was little evidence that taste affected either withdrawal or consumption. These results do not challenge the view that drug tolerance can be context-specific, but suggest that, with the methods used here, morphine withdrawal and consumption may be unaffected by cues associated with the drug.
\end{abstract}

Recent evidence has suggested that the development of tolerance-a decrease in response to a drug after repeated administration-may involve learning (Baker \& Tiffany, 1985; Eikelboom \& Stewart, 1982; Siegel, 1979, 1983). According to one Pavlovian theory (Siegel, 1975), tolerance is the result of learned associations between the drug effects and the environmental cues that precede drug administration. In this theory, after repeated pairings, the environmental context in which a drug is administered elicits a compensatory, drug-opposite response that prepares the organism for the impending upset of homeostasis. The response to the drug is thereby decreased; this constitutes tolerance. Like other models that emphasize a role for learning (e.g., Baker \& Tiffany, 1985), this model predicts that tolerance will be context-specific, that is, that tolerance will only occur in the presence of drugassociated cues. Context-specific tolerance has been shown, for example, with the analgesic (e.g., Hinson, Poulos, Thomas, \& Cappell, 1986; Siegel, 1975, 1976) and hyperthermic (Siegel, 1978; but see Eikelboom \& Stewart, 1982; Zelman, Tiffany, \& Baker, 1985) effects of morphine, as well as with that drug's activity-depressing effects (e.g., Mucha, Volkovskis, \& Kalant, 1981). The context-specific response to expected drug effects is not limited to the opiates, however. Tolerance to the hypother-

This research was supported by Grant BNS 86-07208 from the $\mathrm{Na}$ tional Science Foundation (M.E.B., principal investigator). Experiments 1 and 2 constituted part of a thesis submitted by the first author in partial fulfillment of the requirements for a master's degree at the University of Vermont. Address correspondence to either author, Department of Psychology, University of Vermont, Burlington, VT 05405. mic (e.g., Crowell, Hinson, \& Siegel, 1981) and hypnotic (Melchior \& Tabakoff, 1981) effects of ethanol has also been demonstrated to be context-specific. In addition, the results of studies that have demonstrated contextspecific tolerance to the anorexic effects of amphetamine (Poulos, Wilkinson, \& Cappell, 1981) and to the depressant effects of midazolam (King, Bouton, \& Musty, 1987) provide more support for the generalizability of a conditioning model.

The present article is concerned with the application of a compensatory-response model to drug dependence and consumption. Compensatory responses, as indicated, are counterdirectional to a drug's effects. Siegel $(1979,1983)$ has noted that morphine withdrawal symptoms are also often opposite to the drug's unconditioned effects. He therefore suggested that compensatory responses may contribute to withdrawal. This hypothesis suggests that withdrawal may be elicited by stimuli that have been associated with drug administration. Furthermore, the elicitation of withdrawal might lead to self-administration of the drug to reverse its unpleasant symptoms (e.g., Siegel, 1979, 1983). An application of the compensatory-response theory of drug tolerance to drug dependence would thus predict that an organism will (1) experience stronger withdrawal symptoms in the drug-associated environment, and (2) self-administer greater amounts of the drug in the drugassociated context to correct the upset of homeostasis.

Thompson and Ostlund (1965) examined the influence of the drug-associated environment and of the withdrawal environment on readdiction. Rats were trained to drink a morphine solution (the only source of fluid) in a distinctive room until they were dependent on the drug. After 
a period of withdrawal from the drug, which occurred either in the addiction environment or in a novel environment, reacquisition of morphine drinking was studied. Reacquisition took place in the original addiction context for some subjects, whereas others resumed morphine consumption in the withdrawal context. Consistent with a conditioning analysis of dependence, reacquisition occurred more rapidly and animals drank more morphine in the original drug-associated environment than in the alternative environment. However, these results are difficult to interpret because of problems with the experimental design. The two environments were not counterbalanced, and the room that served as the addiction environment for all subjects, and as the withdrawal and readdiction environment for some, was maintained at $70^{\circ} \mathrm{F}$, whereas the alternate environment, in which some subjects underwent withdrawal and readdiction, was $60^{\circ} \mathrm{F}$. Because morphine and withdrawal affect the regulation of body temperature, this situation may have had serious effects on the results.

In a more recent study, Hinson et al. (1986) trained rats to drink morphine in their home cages and then put them through a period of withdrawal. The rats were then given injections of either morphine or saline in a distinctive environment, and were tested for analgesic tolerance. In agreement with a conditioning model, tolerance was greater in the drug-associated context than in the colony room. Finally, in a one-bottle test of morphine consumption, the rats drank greater amounts of the drug in the context associated with morphine injections. These results suggest that a drug-associated context can increase drug consumption, although the role of context-specific withdrawal effects was not assessed.

In contrast, a study that did examine context-specific morphine withdrawal found no support for a conditioning model of dependence. Zellner, Dacanay, and Riley (1984) assessed withdrawal by monitoring rats' preference for a saccharin solution, which is known to decrease during withdrawal (see Parker \& Radow, 1974). Their subjects received a series of either morphine or water injections in a distinctive environment. After the drugadministration phase, while the rats were in withdrawal, preference for saccharin was tested either in the distinctive environment or in the home cage. The testing environment had no effect on saccharin preference, which suggests that withdrawal, at least as assessed in this somewhat unusual manner, was not affected by the drug-associated environment.

The present experiments were designed to examine the role of conditioning in controlling both withdrawal and self-administration of morphine. Rats initially were given a morphine solution as their only source of fluid. In the first two experiments, two distinctive room and cage environments were used, and the impact of their association with morphine was assessed on withdrawal and readdiction. Based upon the compensatory-response model, if withdrawal is specific to the room stimuli, the group remaining in the original addiction room would be expected to show stronger withdrawal symptoms than the group that is switched to a different room. And when the group that experiences withdrawal in a different room is returned to the drug-associated environment, the drugassociated cues should once again evoke compensatory responses, and the rats would be expected to consume the drug more readily.

\section{EXPERIMENT 1}

Experiment 1 consisted of three phases: addiction, withdrawal, and readdiction. Three groups of animals were used; one group received morphine in the last phase only. The groups that received the drug in the first phase differed in whether withdrawal was experienced in the addiction environment (Group Same) or in a different environment (Group Diff); the rooms were counterbalanced. Withdrawal was assessed by monitoring body-weight loss (e.g., Kumar \& Stolerman, 1972; McMillan et al., 1976; Wei, Loh, \& Way, 1973). During the readdiction phase, all animals received morphine in the original addiction environment.

\section{Method}

\section{Subjects}

The subjects were 36 experimentally naive male Wistar rats from Charles River Laboratories that weighed a mean of $298 \mathrm{~g}$ at the beginning of the experiment. Two animals were dropped from the drug groups during the addiction phase and one control was eliminated during the readdiction phase for failure to consume adequate amounts of the available fluid (morphine solution), leaving 11 subjects per group.

\section{Apparatus}

Two distinctive environments were provided by two different sets of cages housed in two different rooms. Room A measured $1.93 \times 2.92 \mathrm{~m}$ and was dimly illuminated by one bare $100-\mathrm{W}$ incandescent bulb. The room was maintained on a 15:9 h light:dark cycle (lights on at $0700 \mathrm{~h}$ ). The plastic opaque cages measured $24 \times 46 \times 15 \mathrm{~cm}$, and approximately $3 \mathrm{~cm}$ of wood shavings covered the bottom. The stainless-steel cage tops had a receptacle for chow and a place where the drinking bottle could be positioned with the metal spout angled downward into the cage. A distinctive smell was provided by Renuzit "Powder Room" air freshener. Room B measured $2.64 \times 3.38 \mathrm{~m}$ and was brightly lit by four overhead fluorescent light fixtures. The light:dark cycle was the same as in Room A. In this room, the rats were housed in standard "hanging" cages, $17 \times 35 \times 17 \mathrm{~cm}$. The cages were constructed with wire mesh floors and fronts, and solid stainless-steel sides and backs. They were barren inside; food and fluids were delivered through the front of the cage. A distinctive smell in this room was provided by Renuzit "Country Kitchen"' air freshener. In both rooms, the rats' drinking bottles were constructed from 250 -ml polypropylene graduated cylinders that were fitted with rubber stoppers and metal spouts. Each animal used the same cylinder for the duration of the experiment. The morphine sulphate and granulated sugar were dissolved in distilled water.

\section{Procedure}

Upon arrival from the supplier, the rats were randomly placed in one of the two environments. After water intake was monitored for 2 days, the animals were matched and assigned to either a drug group or a control group so that there were 12 drug animals and 6 controls in each room. The rats were individually housed with 
ad-lib food throughout the experiment. All experimental manipulations were performed between 1100 and $1300 \mathrm{~h}$ daily; the subjects were weighed and the appropriate solution was replenished. Fluids were available for approximately $22 \mathrm{~h}$ per day.

Addiction (Days 1-43). In an effort to facilitate the rats' acceptance of morphine, the drug groups began the study with a $0.5-\mathrm{mg} / \mathrm{ml}$ concentration of morphine sulphate in a $10 \%$ sucrose solution. After 7 days, the concentration was increased to $1 \mathrm{mg} / \mathrm{ml}$, at which level it remained for the rest of the phase. The control group received $10 \%$ sucrose in distilled water. On Day 41 , after a 12-h fluid deprivation, all animals were subjected to a $2-\mathrm{h}$, two-bottle choice test in which $30 \mathrm{ml}$ of sucrose-water and $30 \mathrm{ml}$ of sucrose-morphine mixture were made available simultaneously. The position of the tubes was counterbalanced. On Days 38-40, prior to the actual test, the rats had received similar practice tests to habituate them to the procedure. For the practice tests, the animals received their usual fluid (sucrose-morphine or sucrose-water) in both drinking tubes.

Withdrawal (Days 44-61). Based upon the mean intake over the last 2 days of the addiction phase and the rats' preference for morphine, the subjects in the drug condition were matched and assigned to two new groups. The rooms were counterbalanced such that half of the subjects in each group came from Environment $A$ and half from Environment B. Animals in Group Same remained in the addiction environment for the withdrawal phase; those in Group Diff were switched to the alternate environment. Half of the controls in each room remained and half were switched. The drug solution was immediately replaced with sucrose-water.

All animals were weighed at $24,30,36$, and $48 \mathrm{~h}$ into withdrawal, and once daily thereafter. For the remainder of the phase, the procedure continued as in the addiction phase, except that the only liquid available was sucrose-water.

Readdiction (Days 62-84). On Day 62, all subjects that had undergone withdrawal in the alternate environment (Group Diff) were returned to their original addiction environment. Controls also were returned to the room in which they had been housed during the first phase. With the exception of preference tests, all animals now received the sucrose-morphine solution as their sole source of fluid. As in the addiction phase, a concentration of $0.5 \mathrm{mg} / \mathrm{ml}$ was used for 7 days, then replaced with the full concentration $(1 \mathrm{mg} / \mathrm{ml})$ for the duration of the experiment. On the first day of this phase, prior to receiving fluid in the usual bottles, all subjects were given sucrosewater and sucrose-morphine in a 2-h two-bottle choice test. An additional preference test was given on Day 11 .
Data Analysis

Analyses of variance (ANOVAs) and planned comparisons were used to analyze the data. The rejection criterion was set at $p=.05$ throughout. Because of the large number of $F \mathrm{~s}$, primarily those with $p s<.05$ will be presented. In all cases, "not significant" means $p>.10$.

\section{Results}

Addiction (Days 1-43). As can be seen in the left panel of Figure 1, all subjects increased their liquid intake from the beginning to the end of this phase. A 3 (group) $\times$ 2 (room) $\times 2$ (days) ANOVA was conducted using the mean amount of liquid consumed for the first 4 days of the phase and the mean amount for the last 4 days prior to preference testing. The results revealed a significant days effect $[F(1,27)=115.75]$ and a significant group effect $[F(2,27)=44.28]$. Analytic comparisons revealed that both drug groups differed significantly from the controls $[F \mathrm{~s}(1,27) \geq 57.82]$, but not from each other $[F(1,27)<1]$. By the end of the phase, the animals in the drug groups were ingesting an average of $201 \mathrm{mg} / \mathrm{kg}$ per day $(77 \mathrm{ml})$.

The results of the preference test conducted at the end of the addiction phase, shown in the right panel of Figure 1, indicated that the rats that had been receiving morphine showed a greater preference for the drug than did the controls. A 3 (group) $\times 2$ (room) ANOVA revealed a significant group effect $[F(2,27)=5.36]$. Both drug groups differed significantly from the controls $\left[F_{\mathrm{s}}(1,27) \geq 6.27\right]$, but not from each other $[F(1,27)<1]$. There was also a significant room effect $[F(1,27)=4.07]$, with animals in Room A consuming more than those in Room B, but there was no significant interaction.

Withdrawal (Days 44-61). The subjects' dependence on morphine was evident by their significant loss in body weight during withdrawal (Figure 2, left panel). A 3 (group) $\times 2$ (room) $\times 6$ (time) ANOVA was conducted using the percent of baseline weight (weight on the first
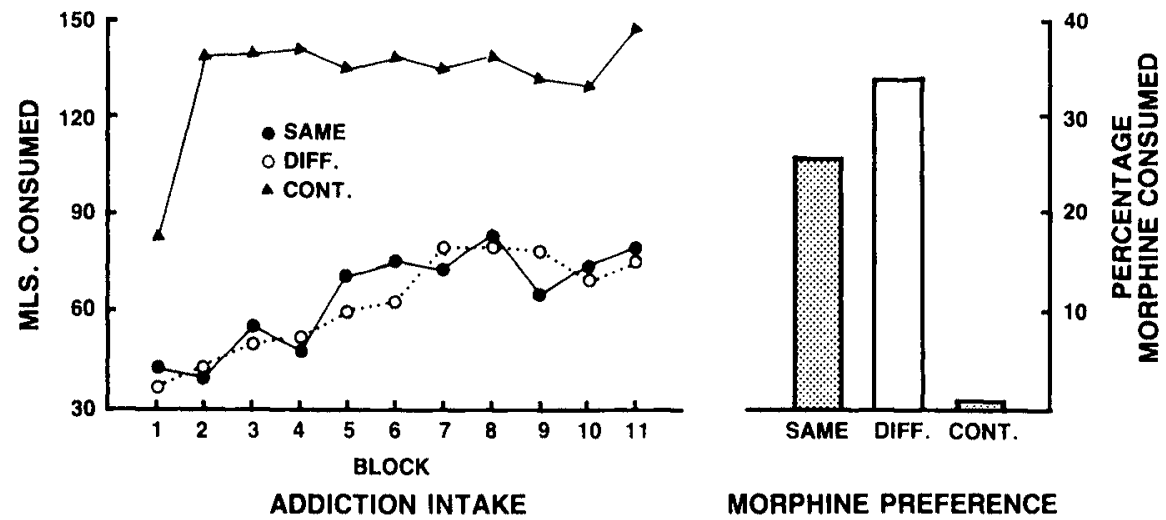

MORPHINE PREFERENCE

Figure 1. Mean daily morphine consumption during the addiction phase of Experiment 1. Data in the left panel are shown in 4-day blocks. Percentage of morphine consumed during the preference test is shown in the right panel. 

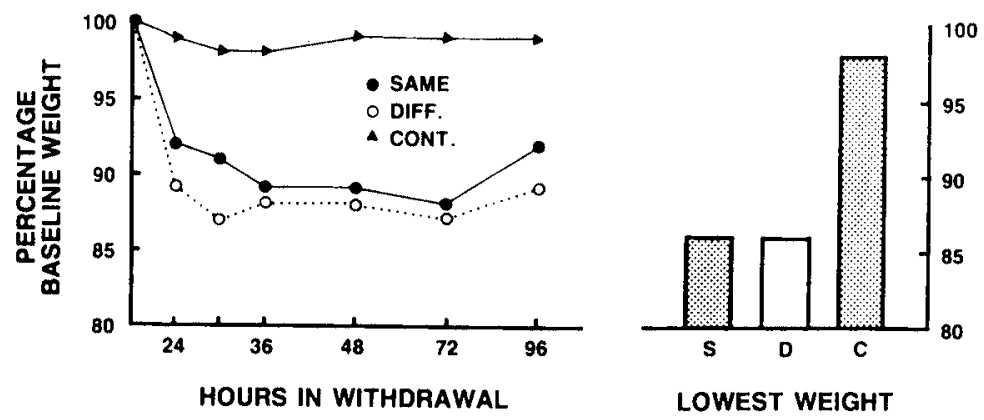

Figure 2. Mean percentage body weight during the withdrawal phase of Experiment 1 . The graph on the right represents the group mean of each animal's lowest weight during the same time period.

morning of withdrawal) for all animals at $24,30,36,48$, 72 , and $96 \mathrm{~h}$ into withdrawal. The results revealed a significant group effect $[F(2,27)=68.66]$. Planned comparisons revealed a significant difference between each drug group and the controls $[F \mathrm{~s}(1,27) \geq 79.89]$ and a significant difference between the two drug groups $[F(1,27)=$ 4.35]. Surprisingly, Group Diff lost more weight than Group Same. The hours effect $[F(5,135)=2.90]$ was also significant. Because each animal varied in exactly when it reached its lowest weight during the withdrawal period, an additional test was run using each animal's lowest percentage of baseline weight (Figure 2, right panel). This test also showed a significant group effect $[F(2,27)=27.73]$, but the lowest mean weight was identical for Group Same and Group Diff $[F(1,27)<1]$. Overall, there was clearly no evidence that withdrawal in the addiction environment (Group Same) led to greater bodyweight loss than withdrawal in a different environment.

Consumption of sucrose-water during the withdrawal phase can be seen in Figure 3. Intake did not differ according to withdrawal context. Using intake for the first 5 days of withdrawal, a $3 \times 2 \times 5$ ANOVA revealed a significant group effect $[F(2,27)=30.0]$. Controls drank more than Groups Same and Diff $[F \mathrm{~s}(1,27) \geq 43.72]$, but the drug groups did not differ from one another $[F(1,27)<1]$. There was a days effect $[F(4,108)=5.51]$.
Further examination of the data showed that intake was lowest on Day 3, when the lowest body weight was also recorded. As can be seen, by the end of this phase animals in the drug groups had increased their intake and were drinking very close to the amount of sucrose-water consumed by controls.

Readdiction (Days 62-84). Based upon the compensatoryresponse model, we expected that animals that were returned to their addiction environment after withdrawal would consume more morphine solution than those that had remained in that environment during withdrawal. However, morphine consumption during readdiction did not differ between drug groups, which suggests that the amount of drug consumed was not affected by context. Morphine consumption during readdiction is shown in Figure 4 (left panel). A $3 \times 2 \times 9$ ANOVA was conducted using the amount of morphine solution that was ingested on Days 2-10 of this phase (Day 1 was excluded because of the preference test). There was a significant group effect $[F(2,27)=$ 13.74]. Planned comparisons showed that the controls drank less than Groups Same and Diff $[F \mathrm{~s}(1,27) \geq 18.32]$. Again, the drug groups did not differ $[F(1,27)<1]$. There was a room effect $[F(2,27)=4.33]$; animals in Environment B consumed more than those in Environment A ( 75.5 and $52.3 \mathrm{ml}$, respectively). A significant days effect $[F(8,216)=9.88]$ suggested that intake varied over

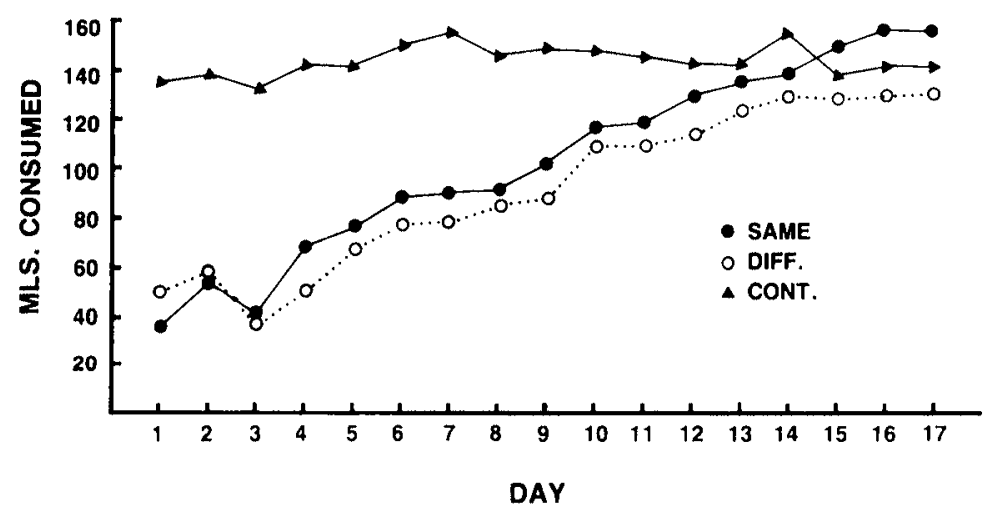

Figure 3. Mean daily sucrose consumption during the withdrawal phase of Experiment 1. 

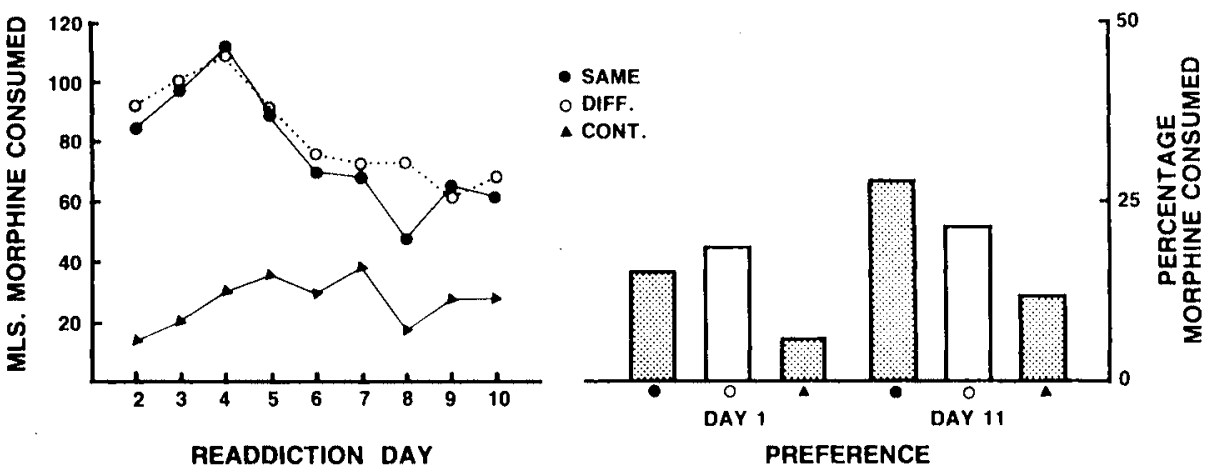

Figure 4. Mean daily morphine consumption during the readdiction phase of Experiment 1 . The results of the preference tests on Days 1 and 11 are shown in the right panel.

days; the subjects decreased their intake after the dose was increased to $1 \mathrm{mg} / \mathrm{ml}$ on Day 6 .

Analysis of the preference tests conducted on Days 1 and 11 of this phase (Figure 4, right panel) showed no group effect or room effect. When given a choice, all animals-drug groups and controls alike-preferred the sucrose-water solution to sucrose-morphine.

\section{Discussion}

The results of this experiment do not support a compensatory-response model as applied to drug dependence. The consumption of morphine during readdiction did not differ between drug groups, which suggests that the environmental stimuli present during the addiction phase had no effect on that aspect of dependence. The data actually indicated significantly greater body-weight loss in Group Diff than in Group Same, a result opposite that predicted by the compensatory-response model, although when the groups were compared using each animal's lowest weight during withdrawal there was no difference between them.

Informal behavioral observations of the animals suggested that the present procedures did not produce an intense withdrawal experience. There were no overt withdrawal symptoms noted in any of the animals. Moreover, irrespective of environment, withdrawal from the drug did little to decrease morphine consumption when it was presented again in the final phase; morphine intake at the beginning of readdiction was close to that at the end of the addiction phase. It is possible, however, that a longer extinction period would be more likely to lead to environment-dependent consumption of morphine during the readdiction phase.

\section{EXPERIMENT 2}

Experiment 2 again tested the impact of environmentdrug associations on the withdrawal and readdiction of subjects made dependent on morphine. In this experiment, the drug-administration procedure was modified. The continuous drug-administration procedure used in Experi- ment 1 may not have been optimal for encouraging an association between environmental cues and the systemic effects of the drug; CS-US pairings that occur at widely spaced intervals may produce better conditioning. A more sudden onset of the drug's effects might also enhance the conditioning process if it results in a stronger compensatory response during drug ingestion. The subjects in Experiment 2 were therefore given the sucrose-morphine solution, their only fluid, for only $2 \mathrm{~h}$ per day.

Several other changes were made in the experimental procedure. First, the subjects were given morphine/ quinine preference tests in addition to the morphine/ sucrose tests. A choice between two similarly bitter fluids and the consumption of a greater percentage of the drug solution would suggest a dependence on morphine. In addition, withdrawal was precipitated with the morphine antagonist naloxone, the subjects were formally observed for withdrawal symptoms, and the withdrawal phase was extended beyond the 17 days used in Experiment 1.

A factorial design was used. The rats were randomly assigned to one of the two environments during the addiction phase. Half of the animals in each environment experienced withdrawal in the same environment and half experienced withdrawal in a different environment. Readdiction then occurred in the withdrawal context for half of each of those groups and in the alternate environment for the other half.

\section{Method}

\section{Subjects}

The subjects were 48 experimentally naive male Wistar rats from Charles River Laboratories that weighed a mean of $192 \mathrm{~g}$ at the beginning of the study. Two animals were dropped during the addiction phase because of inadequate consumption of the morphine solution, leaving a total of 46 subjects for the remainder of the experiment.

\section{Apparatus and Procedure}

The rooms, cages, and equipment were the same as in Experiment 1. Upon arrival from the supplier, the animals were randomly assigned to one of the two environments, where they were housed individually and maintained on ad-lib food and water for 2 days. On the 3 rd day, water was removed and the subjects were deprived 
of fluids for approximately $24 \mathrm{~h}$. Thereafter, the subjects had access to fluids for only $2 \mathrm{~h}$ at the same time each day. Food was available ad lib throughout the experiment.

Addiction (Days 1-33). Four days after arrival, all animals were moved to the alternate environment. This procedure was designed to ensure novelty of the addiction environment at the beginning of the addiction phase. It also gave the rats some exposure to both contexts before they became dependent on morphine. On Day 1 the animals were given their first exposure to the sucrose-morphine solution. As in Experiment 1, the drug concentration was initially $0.5 \mathrm{mg} / \mathrm{ml}$, and was then increased to $1 \mathrm{mg} / \mathrm{ml}$ on Day 6 , at which level it remained for the duration of the study. All animals received sucrose-morphine in this experiment.

All manipulations were performed between 1030 and $1300 \mathrm{~h}$ daily. Body weights were recorded and the sucrose-morphine solution was made available for $2 \mathrm{~h}$. Two-bottle preference tests were conducted on Days 27, 29, and 31. In this experiment, the animals were given a choice between their usual sucrose-morphine solution or a $10 \%$ sucrose solution with $0.23 \mathrm{mg} / \mathrm{ml}$ of quinine hydrochloride. A pilot experiment suggested that this solution was approximately equal in palatability to $1 \mathrm{mg} / \mathrm{ml}$ morphine sulphate mixed with $10 \%$ sucrose. The preference tests lasted $30 \mathrm{~min}$; the subjects then received the usual $1 \mathrm{mg} / \mathrm{ml}$ sucrose-morphine solution alone for $1.5 \mathrm{~h}$. On the intervening days (Days 28 and 30), the animals were first given just the quinine-sucrose solution, then just the sucrose-morphine solution for the usual time.

Withdrawal (Days 34-61). The animals were ranked according to their mean consumption over the last 4 days of the addiction phase and their preference for morphine, then matched and assigned to two groups $(n=23)$. Group Same remained in the addiction environment and Group Diff was switched to the other environment. Thus, at the beginning of the withdrawal phase there were two new groups, half experiencing withdrawal in the familiar drugadministration context (Group Same) and half experiencing withdrawal in the context that had not been associated with drug administration (Group Diff). As usual, the rooms were counterbalanced between groups.

At the time of day when the subjects had ordinarily received morphine, withdrawal was precipitated with an i.p. injection of $1 \mathrm{mg} / \mathrm{kg}$ of naloxone hydrochloride (see Wei, Loh, \& Way, 1973). The morphine antagonist was administered to the rats in squads of three. Immediately following injection, two observers, blind to experimental conditions, observed the subjects for withdrawal symptoms. Each animal in the squad was observed successively for $1 \mathrm{~min}$ at a time, for a total of $21 \mathrm{~min}$ per squad. The behaviors scored included abnormal posture (slouching posture of the abdomen, crossing of the front paws, or writhing movements), teeth chattering (audible sounds of the teeth clicking together), salivation/swallowing movements (licking movements of the jaw and tongue often accompanied by salivation), and wet-dog shakes (a rotational body shake familiar to those produced when an animal is wet). Each of these behaviors was scored as occurring or not occurring during each 60 -sec observation. The observers scored one squad of rats in each room together to provide an estimate of interobserver agreement, then scored the squads independently, alternating rooms, so that the observers rated the same number of squads in each room. After all observations were completed, the animals received sucrose-water for the usual 2-h time period. Access to sucrose-water continued on the usual $2 \mathrm{~h}$ per day schedule for the entire withdrawal phase.

Body weights were recorded between 3 and $4 \mathrm{~h}$ following the naloxone injection, then daily for 6 days. For the remainder of the phase, liquid intake was recorded daily and the animals were weighed every other day.

Readdiction (Days 62-79). On Day 62, the rats in each of the two withdrawal conditions (Same or Diff context) were further divided into two new groups. As before, the subjects were matched on liquid intake and morphine preference from the addiction phase. In each condition, one group remained in the withdrawal context and the other group received a context switch. Thus, based upon whether the withdrawal and readdiction environments were the same (S) as the addiction environment or different (D), the groups were $\operatorname{SSS}(n=11), \operatorname{SSD}(n=12), \operatorname{SDD}(n=11)$, and $\operatorname{SDS}(n=12)$. For the first 4 days of this final phase, the subjects were given $30 \mathrm{ml}$ of sucrose-morphine $(1 \mathrm{mg} / \mathrm{ml})$ and $30 \mathrm{ml}$ of sucrose-quinine $(0.23 \mathrm{mg} / \mathrm{ml})$ for $30 \mathrm{~min}$ in a two-bottle preference test. This was followed by access to sucrose-morphine for $1.5 \mathrm{~h}$ in the usual drinking containers. On Days 5-8 of this phase, the animals were given a choice between sucrose-morphine and sucrose-water. Again, preference testing was followed by $1.5 \mathrm{~h}$ access to sucrose-morphine alone. On the final 2 days of this phase, the animals again received a 30-min choice between sucrose-water and sucrose-morphine, followed by access to sucrose-morphine alone. On the intervening days that did not involve preference testing, all animals received $2 \mathrm{~h}$ of sucrose-morphine alone.

\section{Results}

Addiction (Days 1-33). As expected, the subjects increased their morphine consumption from the beginning to the end of the phase (see Figure 5, left panel). By the end of the phase, the animals were consuming an average of $90 \mathrm{mg} / \mathrm{kg}$ in a $2-\mathrm{h}$ period. A 2 (withdrawal environment) $\times 2$ (readdiction environment) $\times 2$ (room) $\times 2$ (days) ANOVA was conducted comparing the mean liquid intake for the first 4 days of the addiction phase to the mean intake for the last 4 days. The results indicated a significant days effect $[F(1,38)=100.54]$ with no other
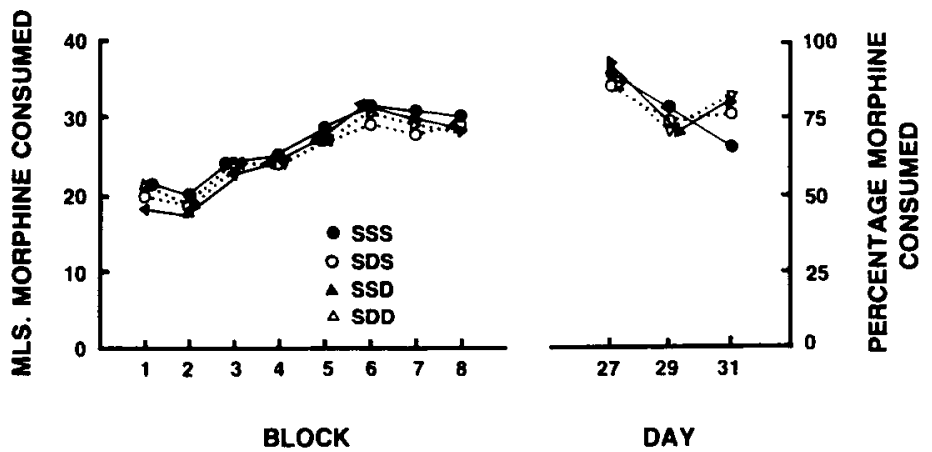

Figure 5. Mean daily morphine consumption during the addiction phase of Experiment 2. Data are shown in 4-day blocks. Percentage of morphine consumed during the preference tests is shown in the right panel. 

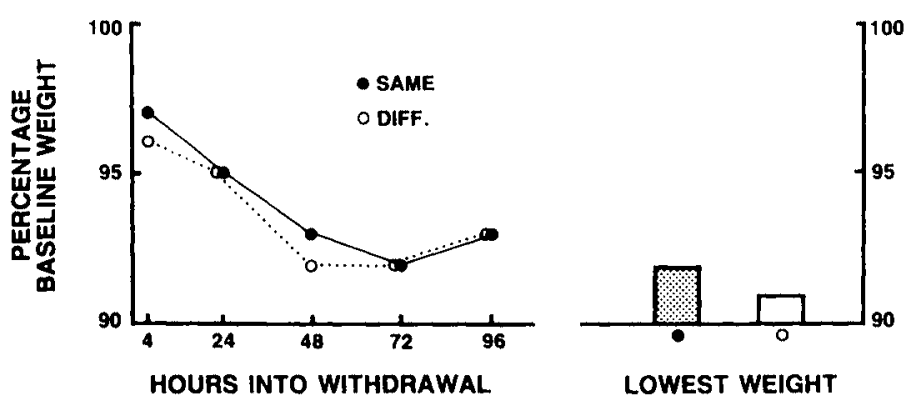

Figure 6. Mean percentage body weight during the withdrawal phase of Experiment 2. The graph on the right represents the group mean of each animal's lowest weight during the same time period.

significant main effects or interactions. This simply indicates increasing morphine intake and that no differences existed between groups prior to the next phase of the experiment.

Analysis of data from the preference tests at the end of this phase (Figure 5, right panel), showed no differences between rooms. There was a marginal day effect $[F(2,76)=2.77, p<.069]$. During the first test, when given a choice between morphine and quinine, the subjects consumed slightly more morphine $(85 \%)$ than on the following test day (74\%). An additional test was run to compare morphine consumption 4 days before the choice tests to total consumption on test days, to investigate whether or not morphine consumption would decrease after access to the quinine. The results revealed no difference in consumption $[F(1,44)=.27]$. The subjects continued to drink their usual amount of the morphine solution despite first having had the opportunity to drink quinine.

Withdrawal (Days 34-61). At this point in the experiment, there were just two groups; those withdrawn from the drug in the same environment, and those withdrawn in a different environment. Morphine dependence was again suggested by significant weight loss during withdrawal. The weight data are summarized in Figure 6. A 2 (group) $\times 2$ (room) $\times 5$ (time) ANOVA was run comparing the subjects' percentage of baseline weight (weight 1 day prior to withdrawal) to weights at $4,24,48,72$, and $96 \mathrm{~h}$ after withdrawal was precipitated. There was a significant hours effect $[F(4,168)=90.03]$, but no effect of the withdrawal environment $[F(1,42)<1]$ or interaction of withdrawal environment and hour $[F(4,168)<1]$. Overall, the lowest weights were recorded $72 \mathrm{~h}$ after withdrawal. An additional ANOVA using each animal's lowest percentage of body weight during withdrawal revealed no main effect for groups $[F(1,42)<1]$, but did show a group $\times$ room interaction $[F(1,42)=4.96]$. For Group Same, the lowest mean weight was in Environment B (90.67\% vs. $93.27 \%$ of baseline in Environment A). For Group Diff, the lowest mean weight was in Environment A (90.5\% vs. $92.27 \%$ of baseline in Environment B).

Behavioral data taken by the blind observers, summarized in Table 1, revealed no difference in the intensity of withdrawal. ANOVAs showed no difference between animals withdrawn in the same or different environments, although there was a marginal effect for teeth chattering $[F(1,44)=3.22, p<.08]$. Group Same exhibited more teeth chattering than Group Diff (all other $p s>.34$ ). Interobserver agreement was $94 \%$ for teeth chattering, $91 \%$ for abnormal posture, and $84 \%$ for salivation/swallowing movements. Wet-dog shakes were observed so infrequently that they were not analyzed. An additional test was run using the total number from all four behavioral observations for each animal. The results again revealed no differences between the groups $[F(1,45)=2.15]$.

Readdiction (Days 62-79). Preference for morphine during readdiction is shown in Figure 7. As in Experiment 1 , morphine intake did not vary as a function of context. The morphine/quinine preference tests given during the first 4 days of readdiction revealed no differences between groups. A 2 (withdrawal environment) $\times 2$ (readdiction environment) $\times 2$ (room) $\times 4$ (day) ANOVA revealed a significant day effect $[F(3,114)=3.88]$. In general, the animals increased their intake of morphine across the 4 test days. No other effects were reliable. When a 2 (withdrawal environment) $\times 2$ (readdiction environment) $\times 2$ (phase) ANOVA was performed comparing the amount of morphine consumed on all preference test days during the addiction and the readdiction phases, a significant phase effect $[F(1,42)=65.14]$ was found. The rats consumed more morphine during the addictionphase preference tests $($ mean $=31 \mathrm{ml}$ ) than during the readdiction-phase preference tests $($ mean $=23 \mathrm{ml}$ ), which suggests that withdrawal decreased the preference for morphine. The first four morphine/sucrose preference tests, conducted on Days 5-8 of this phase, also revealed no differences between groups. A $2 \times 2 \times 2 \times 4$ ANOVA

Table 1

Mean Number (and SD) of Minutes (out of 7) in which Withdrawal Symptoms were Observed (Experiment 2)

\begin{tabular}{lccc}
\hline & \multicolumn{3}{c}{ Symptom } \\
\cline { 2 - 4 } Group & $\begin{array}{c}\text { Abnormal } \\
\text { Posture }\end{array}$ & $\begin{array}{c}\text { Teeth } \\
\text { Chatter }\end{array}$ & $\begin{array}{c}\text { Salivation/ } \\
\text { Swallowing }\end{array}$ \\
\hline Same & $3.30 \pm .48$ & $1.35 \pm .30$ & $1.83 \pm .37$ \\
Diff & $2.78 \pm .50$ & $0.65 \pm .21$ & $1.35 \pm .32$ \\
\hline
\end{tabular}




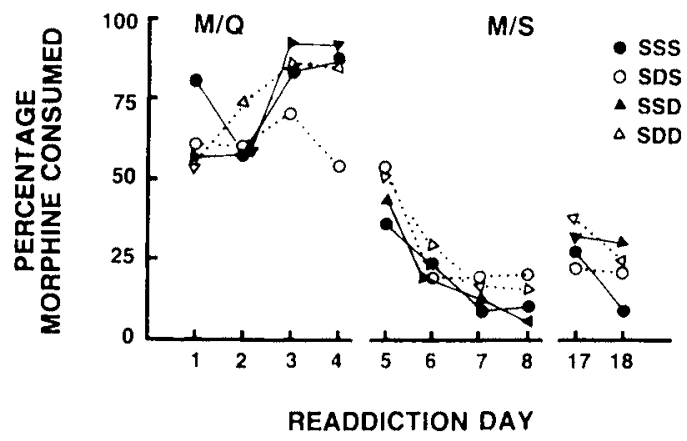

Figure 7. Percentage of morphine consumed during the preference tests of the readdiction phase of Experiment 2. Days 1-4 were morphine/quinine tests; the remaining days were morphine/sucrose tests.

showed a significant day effect $[F(3,114)=19.33]$; the rats increased their preference for sucrose (decreased their preference for morphine) as they were exposed to these tests. When an additional analysis was done comparing the first four morphine/sucrose choice tests to the last two, on Days 17 and 18, the only significant finding was a days $\times$ room interaction $[F(1,38)=4.77]$. Further examination of data showed that all subjects in Room A increased morphine consumption from the first four tests to the last two, whereas all animals in Room B decreased their preference for morphine. There were no group differences, which suggests that neither the withdrawal environment nor the readdiction environment had any effect on the subjects' preference for morphine.

\section{Discussion}

Several improvements were made in Experiment 2 following our failure to find support for a conditioned compensatory-response model in Experiment 1 . First, the animals received morphine for only $2 \mathrm{~h}$ per day. Because the total daily fluid was consumed during this restricted period, the onset of drug effects should have been stronger and more localized in time, possibly providing a stronger US for conditioning. Second, withdrawal was precipitated with naloxone, which created a more abrupt and behaviorally intense withdrawal for all animals. Third, other indexes of withdrawal, besides body-weight loss, were evaluated. The monitoring of some of the classic indexes of withdrawal, however, revealed nothing to indicate that withdrawal was more intense in the drug-associated context than in the context not associated with morphine. The large number of subjects in each group during withdrawal $(n=23)$ make these null results more compelling. Finally, although the withdrawal phase was lengthened in this experiment, which allowed more time for the extinction of drug-associated cues for those withdrawing in the addiction context, there was once again no difference in morphine consumption when the drug was offered again in the third (readdiction) phase. Using this paradigm, the results of Experiments 1 and 2 provide no support for the view that room and cage stimuli affect drug withdrawal or consumption.

\section{EXPERIMENT 3}

It is possible that with the procedures used in Experiments 1 and 2, the most salient drug cues may not have been the cages or rooms in which the animals were housed. For the rat, different stimuli may be differentially associable with drug effects. Rats may tend to associate internal changes with gustatory and olfactory cues (Domjan \& Wilson, 1972; Garcia \& Koelling, 1966; Gemberling \& Domjan, 1982). In a study of naloxone-precipitated withdrawal in the presence of gustatory and audiovisual stimuli, rats subsequently avoided a gustatory cue but not an audiovisual one (Frumkin, 1975). Postingestional effects may be more readily associated with taste because the two events are interoceptively located (Rozin \& Kalat, 1971), or because the similarity in location and temporal pattern (onset) may cause taste and postingestional effects to become associated (Testa, 1975). Unlike the contextual stimuli manipulated in Experiments 1 and 2, taste is a discrete stimulus present only at the time of drug administration. In the present study, the taste of sucrose and morphine may have been salient enough to overshadow (Pavlov, 1927) the room and cage stimuli that were manipulated.

Experiment 3 was therefore designed to manipulate taste rather than environment. Rats were given a saccharinmorphine solution during the addiction phase (saccharin replaced sucrose here so that taste would not be confounded with caloric value). During the withdrawal phase, the rats received either saccharin-quinine (Group SaccharinQuinine) or plain water (Group Water). Saccharin-quinine has a bittersweet taste similar to saccharin-morphine. If conditioned preparatory responses are specific to taste, Group Saccharin-Quinine would be expected to experience a more intense withdrawal. In the readdiction phase, all animals once again received the saccharin-morphine solution. For Group Water, the bittersweet taste of the drug solution should still be associated with the drug effects. This group would be expected to drink more than Group Saccharin-Quinine.

\section{Method}

\section{Subjects}

The subjects were 36 female Wistar rats bred at the University of Vermont that weighed a mean of $253 \mathrm{~g}$ at the beginning of the study. Eighteen of the animals were dropped during the addiction phase due to failure to consume the saccharin-morphine solution, leaving 9 subjects per group.

\section{Apparatus and Procedure}

Since taste, rather than environment, was manipulated in this experiment, all animals were individually housed in one of the rooms used previously, Room B. Cages, lighting, equipment, and basic procedures were the same as in Experiments 1 and 2. After being placed in the experimental room, the subjects were given water for $2 \mathrm{~h}$ daily for 2 days to accustom them to the drinking schedule that would be followed throughout the study. Food was available ad lib.

Addiction (Days 1-51). As in the first two experiments, morphine sulfate was dissolved in distilled water. However, $0.05 \%$ saccharin was used as the sweetener in this experiment. A pilot study suggested that this concentration of saccharin was roughly equal in palat- 
ability to the $10 \%$ sucrose used previously. Saccharin was used to ensure that any loss in weight during withdrawal in Group Water would not be due to a reduction in caloric intake. All animals received saccharin-morphine for the entire phase. We began the phase with a full dose of morphine $(1 \mathrm{mg} / \mathrm{ml})$, but after 4 days the dose was reduced to $0.5 \mathrm{mg} / \mathrm{ml}$ for 1 week because of inadequate consumption of fluids by the animals. The dose was then increased to $1 \mathrm{mg} / \mathrm{ml}$, at which level it remained for the rest of the experiment. As in Experiment 2, manipulations were carried out between 1030 and $1300 \mathrm{~h}$ daily. Body weights were recorded and the subjects had access to the drug solution for $2 \mathrm{~h}$.

Withdrawal (Days 52-89). The animals were randomly assigned to either Group Water or Group Saccharin-Quinine. During the withdrawal phase, Group Water received plain distilled water, whereas Group Saccharin-Quinine received $0.05 \%$ saccharin with $0.23 \mathrm{mg} / \mathrm{ml}$ of quinine hydrochloride. On the first day of withdrawal, the rats were weighed and then received the appropriate solution for $10 \mathrm{~min}$. They were then given an i.p. injection of $1 \mathrm{mg} / \mathrm{kg}$ of naloxone hydrochloride. Immediately after all animals were injected, drinking bottles were replaced, and experimenters, blind to the group assignments, observed the rats for withdrawal behaviors for the next $42 \mathrm{~min}$. The behaviors included abnormal posture, salivation/ swallowing movements, teeth chattering, and wet-dog shakes, and were scored as occurring or not occurring during each minute of observation. The rats' cages were positioned in rows of three. For each row, observers watched 2 rats at a time for 1 min (the center animal was observed by both experimenters to provide an estimate of interobserver agreement). Rows were observed successively until each row was observed for a total of $7 \mathrm{~min}$. The drinking bottles remained on the cages for a total of $2 \mathrm{~h}$.

In addition to the preinjection weight, body weights were recorded at $6,24,48,72$, and $96 \mathrm{~h}$ postinjection, then on an average of every other day for the remainder of the study. Liquid intake was recorded daily.

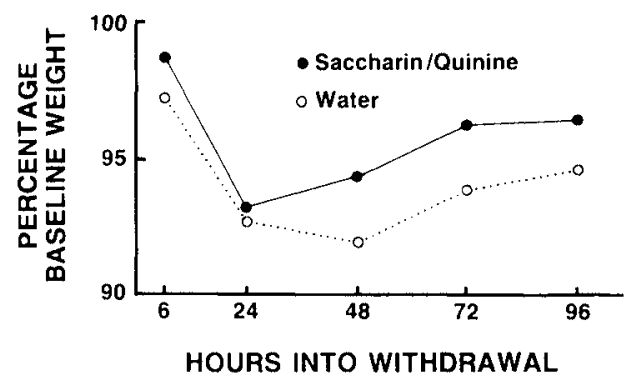

Figure 8. Mean percentage body weight during the withdrawal phase of Experiment 3.

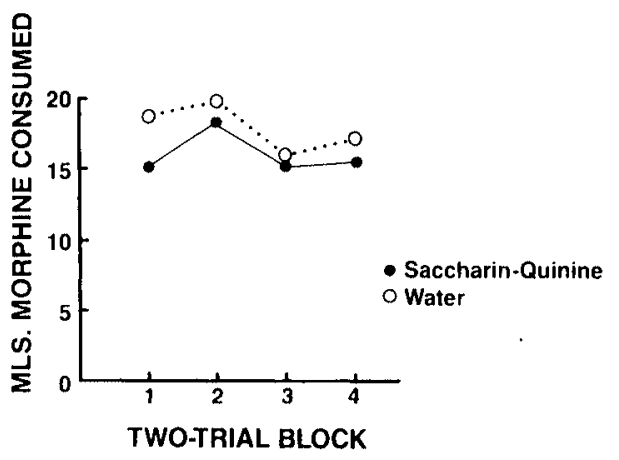

Figure 9. Mean daily morphine consumption during the readdiction phase of Experiment 3. Data are shown in 2-day blocks.
Table 2

Mean Number (and SD) of Minutes (out of 6)

in which Withdrawal Symptoms were Observed (Experiment 3)

\begin{tabular}{|c|c|c|c|c|}
\hline \multirow[b]{2}{*}{ Group } & \multicolumn{4}{|c|}{ Symptom } \\
\hline & $\begin{array}{c}\text { Abnormal } \\
\text { Posture }\end{array}$ & $\begin{array}{c}\text { Teeth } \\
\text { Chatter }\end{array}$ & $\begin{array}{l}\text { Salivation/ } \\
\text { Swallowing }\end{array}$ & Tremors \\
\hline $\begin{array}{l}\text { Saccharin/ } \\
\text { Quinine }\end{array}$ & $4.22 \pm .64$ & 0.00 & $1.55 \pm .34$ & $0.44 \pm .18$ \\
\hline Water & $4.55 \pm .58$ & $0.11 \pm .11$ & $1.55 \pm .34$ & $1.00 \pm .60$ \\
\hline
\end{tabular}

Readdiction (Days 90-97). During the final phase, all animals were once again given $1 \mathrm{mg} / \mathrm{ml}$ of saccharin-morphine solution for the usual $2 \mathrm{~h}$ per day.

\section{Results}

Addiction (Days 1-51). The subjects decreased their consumption from baseline by $14 \mathrm{ml}$ on Day 1 when a new taste, the saccharin-morphine solution, was offered. However, as in the first two experiments, the subjects increased their intake from the beginning to the end of this phase. When a 2 (group) $\times 2$ (time) ANOVA was conducted comparing the first 4 days to the last 4 days of this phase, the results indicated a significant time effect $[F(1,16)=276.004]$. The animals consumed an average of $21 \mathrm{ml}(79 \mathrm{mg} / \mathrm{kg})$ of morphine in a 2-h period by the end of the phase.

Withdrawal (Days 52-89). Body weight during withdrawal is shown in Figure 8. As can be seen, the weight loss was similar to that in Experiment 2 and again suggested that the rats had become dependent on the drug. A 2 (group) $\times 5$ (time) ANOVA was run using the animals' percentage of baseline weight at $6,24,48,72$, and $96 \mathrm{~h}$ after withdrawal was precipitated with naloxone. There was a significant time effect $[F(4,56)=2.63]$; overall weight loss was equally low at 24 and $48 \mathrm{~h}$ after withdrawal. There was also a significant time $\times$ group effect $[F(4,56)=2.98]$. Group Water's lowest weight was recorded at $48 \mathrm{~h}$, whereas Group Saccharin-Quinine reached its lowest weight at $24 \mathrm{~h}$. The group main effect was not significant $[F(1,14)=1.29]$. Additional confirmation was obtained when each animal's lowest weight during withdrawal was analyzed $[F(1,16)=2.42$; mean for Group Water $=92 \%$ of baseline, mean for Group Saccharin-Quinine $=93 \%$ of baseline]. When a 2 (group) $\times 6$ (time) ANOVA was run using the intake for the first 6 days of withdrawal, the results indicated that intake of fluids did not differ between the groups $[F(1,16)<1]$.

The data from behavioral observations are presented in Table 2. The results revealed no group differences in the intensity of withdrawal on any index [all $p \mathrm{~s}>.1$ ]. Interobserver agreement was $86 \%$ for abnormal posture, $100 \%$ for teeth chattering, and $80 \%$ for salivation/ swallowing movements. As in Experiment 2, wet-dog shakes occurred very infrequently and therefore were not analyzed.

Readdiction (Days 90-97). Figure 9 shows fluid intake during the readdiction phase. A 2 (group) $\times 4$ (time) ANOVA was run analyzing intake of saccharin-morphine in 2-day blocks for the $\mathbf{8}$ days of this phase. No difference 
in consumption was found between the groups $[F(1,16)=$ 1.08]. When morphine consumption on the first day of readdiction was compared to liquid intake on the last day of withdrawal, there were no group differences $[F(1,16)=1.89]$, nor did the groups differ in consumption of the drug when the last day of addiction was compared to the first day of readdiction $[F(1,16)=1.78]$. As in the previous experiments, stimuli associated with morphine had no effect on withdrawal or consumption.

\section{Discussion}

The sweet-bitter taste of saccharin-morphine may have been an especially effective cue for the drug. However, manipulation of that taste did not indicate that it affected any aspect of dependence. Group Water did not show either weaker withdrawal symptoms or a stronger tendency to consume morphine again during the final phase than did the group that received a sweet-bitter flavor throughout the withdrawal (extinction) phase. It is possible that the substitution of water for the sweet saccharinmorphine flavor could have initiated an emotional reaction (see Flaherty \& Rowen, 1986) that may have led to some weight loss in Group Water. Although this would have led us to overestimate weight loss associated with morphine withdrawal in the water context, a control study indicated that water introduced after comparable exposure to saccharin alone does not stimulate weight loss. Thus, it may be safe to conclude that, at least as manipulated here, taste cues associated with morphine had no effect on the intensity of withdrawal or the tendency to consume morphine again during readdiction.

\section{GENERAL DISCUSSION}

The aim of the present experiments was to investigate the role of conditioning in controlling withdrawal and the oral self-administration of morphine. However, we obtained little evidence that would recommend applying a compensatory-response model to drug dependence as produced by the present methods. There can be little doubt that our methods made the animals dependent on morphine; removal of the drug produced a significant loss in body weight in each experiment as well as behavioral symptoms of withdrawal in Experiments 2 and 3 . However, drug-associated cage and room stimuli (Experiments 1 and 2) and taste stimuli (Experiment 3) appear to have had little impact on the consumption of morphine, the intensity of withdrawal symptoms, or the tendency to relapse.

Such results might be explained if the animals failed to discriminate between the stimuli that were manipulated in these experiments. However, the context-specificity of morphine tolerance has been demonstrated in environments that have differed along many of the same physical dimensions as did ours (e.g., Hinson et al., 1986). When one considers the rat's ability to learn about a variety of exteroceptive contexts (e.g., Balsam \& Tomie,
1985), it seems unlikely that the cage and room stimuli used in the present study were not different enough for the animals to discriminate between them. In addition, the fact that Group Diff showed a greater weight loss than Group Same during withdrawal in Experiment 1, although opposite to the outcome predicted, can be interpreted as evidence that our environments had a differential impact on the animals. Finally, there can be little question that the tastes manipulated in Experiment 3 were discriminable to the rats. The present experiments were consistent in demonstrating little control over morphine withdrawal and consumption by a reasonable range of stimuli.

It is possible that, contrary to the compensatory-response model, cues associated with morphine may sometimes mimic the effects of the drug rather than oppose them. Under some circumstances, stimuli associated with morphine injections may reverse or prevent morphinewithdrawal hypothermia (Drawbaugh \& Lal, 1974; Roffman, Reddy, \& Lal, 1973). Such a tendency may have reduced withdrawal symptoms in the presence of morphine cues in the present experiments. In a similar vein, there is some evidence that suggests that withdrawal might be elicited by cues associated with withdrawal rather than by cues associated with morphine (see Wikler $\&$ Pescor, 1967). Either of these effects could obscure the conditional effects under investigation here. Like the effects predicted by the compensatory-response model, however, neither effect was observed directly here.

Other mechanisms may have complicated our search for stronger withdrawal symptoms in the drug-associated context. It is possible that the novel environment may have been stressful for the subjects switched to a new context for withdrawal in Experiments 1 and 2. Stressful stimulation may result in the activation of endogenous analgesic mechanisms (Bardo \& Hughes, 1979; Tiffany, Petri, Baker, \& Dahl, 1983). In the rat, endogenous opioids might be released as part of the animal's defensive behavior system (e.g., Fanselow \& Sigmundi, 1986; Lester \& Fanselow, 1985), which might modify the effects of morphine (e.g., see Stewart \& Eikelboom, 1981). It seems unlikely, however, that novelty-induced stress responses would explain our null results. Since an endogenous opioid might substitute for morphine, its release during withdrawal in the switched animals would have magnified, rather than reduced, the predicted difference between our groups during withdrawal. Furthermore, the switched subjects in Experiment 3 received only water, a familiar solution that by itself should not induce stress. Thus, stress could not have played a consistent role across the present experiments.

As a final relevant issue, there is some evidence that suggests that context-specific tolerance may not develop if the CS is presented for relatively long durations on conditioning trials (Paletta \& Wagner, 1986). The long exposures to the environmental and taste cues used in the present experiments may not have been optimal for the conditioning of compensatory responses. However, this 
possibility would further reinforce the view that compensatory responses were not the cause of the reliable withdrawal symptoms that were observed in the present study.

The results of the present experiments are compatible with previous research that has suggested that morphine withdrawal is not controlled by stimuli associated with the drug (Zellner et al., 1984). However, our results contrast with those of earlier studies that suggested that oral morphine consumption may be controlled, at least partly, by environment-drug associations (Hinson et al., 1986; Thompson \& Ostlund, 1965). As noted earlier, the Thompson and Ostlund experiment is difficult to interpret because their environments differed radically in temperature and were not counterbalanced. The Hinson et al. experiment is not so easily questioned, although it involved methods that differed quite substantially from ours. For example, Hinson et al. injected morphine every 4 days during conditioning, whereas our morphine was administered orally and daily. Their experiment was also considerably longer (lasting almost 500 days), involved lengthy periods of drug exposure and drug withdrawal prior to the conditioning phase, and involved restricted access to the experimental environment and to food. Any of a number of differences between the two studies might thus explain the discrepancy in outcomes. Our oral administration procedure did produce reliable drug dependence, however, and that dependence was not demonstrably affected by gustatory or external stimuli associated with the drug.

The present data do not challenge the view that morphine tolerance can depend on classical conditioning (e.g., Baker \& Tiffany, 1985; Eikelboom \& Stewart, 1982; Siegel, 1975, 1976, 1979, 1983). Instead, if one accepts that tolerance does involve learning, then the present results suggest that tolerance may not be linked directly to other aspects of drug dependence. A looser connection between tolerance, withdrawal, and consumption may occur if the compensatory responses that control tolerance do not provide the basis for drug withdrawal (see Siegel, 1979, 1983). Alternatively, tolerance may involve other learning processes with no necessary connection to withdrawal or drug consumption (e.g., Baker \& Tiffany, 1985). It should also be borne in mind that withdrawal itself-either conditioned or unconditioned-may not be necessary to motivate drug consumption (e.g., Stewart, de Wit, \& Eikelboom, 1984). The present data suggest that it may be important to distinguish the processes involved in drug tolerance from those that support other aspects of drug dependence.

\section{REFERENCES}

BAKER, T. B., \& TIFfanY, S. T. (1985). Morphine tolerance as habituation. Psychological Review, 92, 78-108.

Balsam, P. D., Tomie, A. (1985). Context and learning. Hillsdale, NJ: Erlbaum.

BARDO, M. T., Hughes, R. A. (1979). Exposure to a nonfunctional hot plate as a factor in the assessment of morphine-induced analgesia and analgesic tolerance in rats. Pharmacology, Biochemistry \& Behavior, 10, 481-485.
Crowell, C. R., Hinson, R. E., \&iegel, S. (1981). The role of conditioned drug responses in tolerance to the hypothermic effect of ethanol. Psychopharmacology, 21, 51-54.

Domjan, M., WIIsON, N. E. (1972). Specificity of cue to consequence in aversion learning in the rat. Psychonomic Science, 26, 143-145.

Drawbaugh, R., Lal, H. (1974). Reversal by narcotic antagonist of a narcotic action elicited by a conditional stimulus. Nature, 247 , 65-67.

EIKElboOm, R., \& Stewart, J. (1982). The conditioning of druginduced physiological responses. Psychological Review, 89, 507-528.

FANSELOW, M. S., \& SigmUNDI, R. A. (1986). Species-specific danger signals, endogenous opioid analgesia, and defensive behavior. Journal of Experimental Psychology: Animal Behavior Processes, 12 , 301-309.

Flaherty, C. F., \& Rowen, G. (1986). Successive, simultaneous, and anticipatory contrast in the consumption of saccharin solutions. Journal of Experimental Psychology: Animal Behavior Processes, 12, 381-393.

Frumkin, K. (1975). Differential potency of taste and audiovisual stimuli in the conditioning of morphine withdrawal in rats. Psychopharmacologia (Berlin), 46, 245-248.

GarCiA, J., Koelling, R. A. (1966). Relation of cue to consequence in avoidance learning. Psychonomic Science, 4, 123-124.

Gemberlung, G. A., Domjan, M. (1982). Selective associations in one-day-old rats: Taste-toxicosis and texture-shock aversion learning. Joumal of Comparative \& Physiological Psychology, 96, 105-113.

Hinson, R. E., Poulos, C. X., Thomas, W. . Cappell, H. (1986). Pavlovian conditioning and addictive behavior: Relapse to oral selfadministration of morphine. Behavioral Neuroscience, 100, 368-375.

King, D. A., Bouton, M. E., \& Musty, R. E. (1987). Associative control of tolerance to the sedative effects of a short-acting benzodiazepine. Behavioral Neuroscience, 101, 104-114.

Kumar, R., \& Stolerman, I. P. (1972). Resumption of morphine selfadministration by ex-addict rats. Journal of Comparative \& Physiological Psychology, 78, 457-465.

LESTER, L. S., FANSELow, M. S. (1985). Exposure to a cat produces opioid analgesia in rats. Behavioral Neuroscience, 99, 756-759.

McMillan, D. E., Leander, J. D., Wilson, T. W., Wallace, S. C., Fox, T., Redding, S., \&URK, R. T. (1976). Oral injection of narcotic analgesics in rats. Joumal of Pharmacology \& Experimental Therapeutics, 196, 269-279.

MELChIOR, C. L., TABAKOFF, B. (1981). Modification of environmentally-cued tolerance to ethanol in mice. Joumal of Pharmacology \& Experimental Therapeutics, 219, 175-180.

Mucha, R. F., Volkovskis, C., Kalant, H. (1981). Conditioned increases in locomotor activity produced with morphine as an unconditioned stimulus, and relation of conditioning to acute morphine effect and tolerance. Journal of Comparative \& Physiological Psychology, 95, 351-362.

Paletta, M. S., \& Wagner, A. R. (1986). Development of contextspecific tolerance to morphine: Support for a dual-process interpretation. Behavioral Neuroscience, 100, 611-623.

PARKer, L., RADOW, B. (1974). Morphine-like physical dependence: A pharmacologic method for drug assessment using the rat. Pharmacology, Biochemistry \& Behavior, 2, 613-618.

Pavlov, I. P. (1927). Conditioned reflexes (G. V. Anrep, Trans.). London: Oxford University Press.

Poulos, C. X., Wilkinson, D. A., CAPpell, H. (1981). Homeostatic regulation and Pavlovian conditioning in tolerance to amphetamineinduced anorexia. Journal of Comparative \& Physiological Psychol ogy, 95, 735-746.

Roffman, M., Reddy, C., \& LAL, H. (1973). Control of morphinewithdrawal hypothermia by conditional stimuli. Psychopharmacologia, 29, 197-201.

Rozin, P., Kalat, J. W. (1971). Specific hungers and poison avoidance as adaptive specializations of learning. Psychological Review, 78, 459-487.

SIEGEL, S. (1975). Evidence from rats that morphine tolerance is a learned response. Journal of Comparative \& Physiological Psychology, 89, 498-506.

SIEGEL, S. (1976). Morphine analgesic tolerance: Its situation specificity supports a Pavlovian conditioning model. Science, 193, 323-325. 
SIEGEL, S. (1978). Tolerance to the hyperthermic effect of morphine in the rat is a learned response. Journal of Comparative \& Physiological Psychology, 92, 1137-1149.

SIEGEL, S. (1979). The role of conditioning in drug tolerance and addiction. In J. D. Keehn (Ed.), Psychopathology in animals: Research and clinical applications (pp. 143-168). New York: Plenum.

Siegel, S. (1983). Classical conditioning, drug tolerance, and drug dependence. In Y. Israel, F. B. Glaser, H. Kalant, R. E. Popham, W. Schmidt, \& R. G. Smart (Eds.), Research advances in alcohol and drug problems (pp. 207-246). New York: Plenum.

Stewart J., de Wit, H., \& Eikelboom, R. (1984). Role of unconditioned and conditioned drug effects in the self-administration of opiates and stimulants. Psychological Review, 91, 251-268.

STEWART, J., \& EIKELBOOM, R. (1981). Interaction between the effects of stress and morphine on body temperature in rats. Life Sciences, 28, 1041-1045.

TESTA, T. J. (1975). Effects of similarity of location and temporal intensity pattern of conditioned and unconditioned stimuli on the acquisition of conditioned suppression in rats. Journal of Experimental Psychology: Animal Behavior Processes, 104, 114-121.

Thompson, T., \& OsrLund, W. (1965). Susceptibility to readdiction as a function of the addiction and withdrawal environments. Journal of Comparative \& Physiological Psychology, 60, 388-392.
Tiffany, S. T., Petrie, E. C., Baker, T. B., Dahl, J. L. (1983). Conditioned morphine tolerance in the rat: Absence of a compensatory response and cross-tolerance with stress. Behavioral Neuroscience, 97, 335-353.

WEI, E., LOH, H., \& WAY, E. (1973). Quantitative aspects of precipitated abstinence in morphine-dependent rats. Journal of Pharmacology \& Experimental Therapeutics, 184, 398-403.

WIKLER, A., \& PEscor, F. T. (1967). Classical conditioning of a morphine abstinence phenomenon, reinforcement of opioid-drinking behavior and "relapse" in morphine addicted rats. Psychopharmacologia, 10, 255-284.

Zeluner, D. A., DaCanay, R. J., \& RrueY, A. L. (1984). Opiate withdrawal: The result of conditioning or physiological mechanisms? Pharmacology, Biochemistry \& Behavior, 20, 175-180.

Zelman, D. C., Tiffany, S. T., \& Baker, T. B. (1985). Influence of stress on morphine-induced hyperthermia: Relevance to drug conditioning and tolerance development. Behavioral Neuroscience, 99, 122-144.

(Manuscript received July 25, 1988; revision accepted for publication December 27, 1988.) 